С. В. Габелков, Р. В. Тарасов, Н. С. Полтавцев, М. П. Старолат, А. В. Пилипенко, А. Г. Миронова, В. В. Макаренко, Ф. В. Белкин

ННЦ “Харьковский физико-технический институт»

\section{Спекание кубического}

\section{оксида циркония - матрицы для иммобилизации}

\section{ВыСОКОаКТИВНЫХ ОТХОДОВ}

Исследовано спекание компактов из наноразмерного порошка кубического оксида циркония, содержащего $10 \%$ масс. оксида иттрия (стабилизатор) и $15 \%$ масс. оксида европия (имитатор актиноида америция). Керамическая матрица для иммобилизации актиноидов из кубического оксида циркония с относительной плотностью 95,4\%, с зернами размерами 4-6 мкм и порами трех интервалов размеров (0,85-1,1 мкм, 0,4-0,6 мкм и 0,2-0,3 мкм) получена при оптимальной температуре $1400^{\circ} \mathrm{C}$ в течение 14. Спекание проходит интенсивно при температурах $900-1200{ }^{\circ} \mathrm{C}$ и менее активно - при $1200-1400{ }^{\circ} \mathrm{C}$ с энергиями активаций

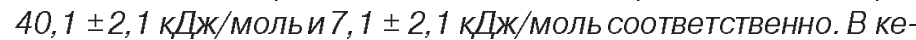
рамическомматериале наблюдается умеренный $\left(700-900{ }^{\circ} \mathrm{C}\right)$ и интенсивный $\left(900-1400^{\circ} \mathrm{C}\right)$ рост зерен с энергиями активаций 12,8 $\pm 5,1$ кДж/моль и $191 \pm 10$ КДж/моль соответственно.

С. В. Габєлков, Р. В. Тарасов, М. С. Полтавцев, М. П. Старолат, О. В. Пилипенко, А. Г. Миронова, В. В. Макаренко, Ф. В. Белкін

\section{Спікання кубічного оксиду цирконію - матриці для іммобілізації високоактивних відходів}

Досліджено спікання компактів з нанорозмірного порошку кубічного оксиду цирконію, що містить $10 \%$ мас. оксиду ітрію (стабілізатор) та $15 \%$ мас. оксиду європію (імітатор актиноїду америцію). Керамічну матрицю для іммобілізації актиноїдів з кубічного оксиду цирконію з відносною густиною 95,4\%, із зернами розміром 4-6 мкм іпорами трьох інтервалів розмірів (0,85-1,1 мкм, 0,4-0,6 мкм і 0,2-0,3 мкм) отримано при оптимальній температурі $1400^{\circ} \mathrm{C}$ впродовж 1 год. Спікання відбувається інтенсивно в інтервалі температур 900-1200 ${ }^{\circ} \mathrm{C}$ іменш активно - при $1200-1400{ }^{\circ} \mathrm{C}$ з енергіями

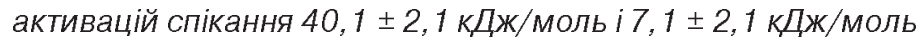
відповідно. Укерамічному матеріалі спостерігається помірне $\left(700-900{ }^{\circ} \mathrm{C}\right)$ й інтенсивне $\left(900-1400{ }^{\circ} \mathrm{C}\right)$ зростання зерен

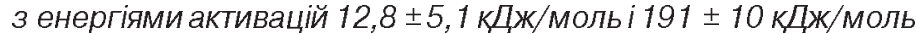
відповідно.
$\mathrm{K}$ убический оксид циркония благодаря привлекательности своих электротехнических, химических и механических свойств нашел применение в качестве топливных ячеек, нагревателей высокотемпературных печей, носителей катализаторов, тиглей и других изделий в энергетике, электротехнике и химической промышленности. Специалистов атомной энергетики привлекает повышенная радиационная и коррозионная стойкость оксида циркония. Благодаря этому он вызывает интерес у исследователей для создания материалов мишеней для трансмутации актиноидов, матричного топлива и матриц для изоляции радиоактивных отходов [1]-[5].

В течение последнего десятилетия в ряде исследовательских организаций Европы ведутся работы по трансмутации плутония и дочерних актиноидов нептуния, америция и кюрия в тепловых реакторах с использованием матриц из оксида циркония. Надежность проведения трансмутации плутония и актиноидов обеспечена высокой радиационной стойкостью кубического оксида циркония [2].

Для включения актиноидов в керамическую матрицу необходимо учитывать особенности всех процессов, происходящих при ее получении, в том числе и спекания кубического оксида циркония для получения монолитного беспористого материала, обеспечивающего надежную иммобилизацию радионуклидов. Актиноиды, как большинство искусственно созданных элементов, обладают высокой токсичностью и требуют повышенного внимания при обращении с ними. Ocобенно высокую токсичность имеют изотопы америция [4]. По этой причине эксперименты по иммобилизации плутония и дочерних актиноидов в оксидные матрицы довольно опасны и в связи с этим дорогостоящи. Учитывая вышеизложенное целесообразно максимально бо́льшую часть научных разработок проводить на имитаторах.

Согласно теории Сиборга [6], лантаноиды - приемлемые физико-химические имитаторы актиноидов, поскольку как в ряду лантаноидов, так и в ряду актиноидов идет заполнение электронами не наружной, а внутренней $5 f$ оболочки. С этой точки зрения в силу подобия имитатором америция является европий. Поэтому при создании матриц для иммобилизации дочерних актиноидов целесообразно исследовать особенности спекания и формирования микроструктуры кубического оксида циркония с оксидом европия как имитатором оксида америция.

Целью работы является исследование спекания компактов из наноразмерного порошка кубического оксида циркония с введенным оксидом европия как имитатором оксида америция для получения высокоплотного матричного материала при иммобилизации высокоактивных отходов.

Методика эксперимента. В исследованиях использовали наноразмерный порошок кубического оксида циркония, полученный при термическом разложении гидроксидов циркония, иттрия и европия, совместно осажденных из смеси водных растворов их нитратов [7]. Синтез кубического твердого раствора проводили при $700{ }^{\circ} \mathrm{C}$ в течение 0,5 ч. Средний размер зерен порошка $-17 \pm 2$ нм. Нитраты циркония, иттрия и европия брали в соотношении, позволяющем получить в итоге порошок оксида циркония с $10 \%$ масс. оксида иттрия и $15 \%$ масс. оксида европия.

Образцы в форме таблеток диаметром 14,5 мм и высотой 5 мм готовили методом осевого холодного прессования на гидравлическом прессе. Термообработку образцов проводили в течение 1 ч при температурах 700-1200 ${ }^{\circ} \mathrm{C}$ (через $\left.100{ }^{\circ} \mathrm{C}\right)$ на воздухе в печи СУОЛ-0,25.1/12-М1 и при 1300 и $1400{ }^{\circ} \mathrm{C}$ в вакууме в печи СШВЭ 1.2,5/25ИЗ. 


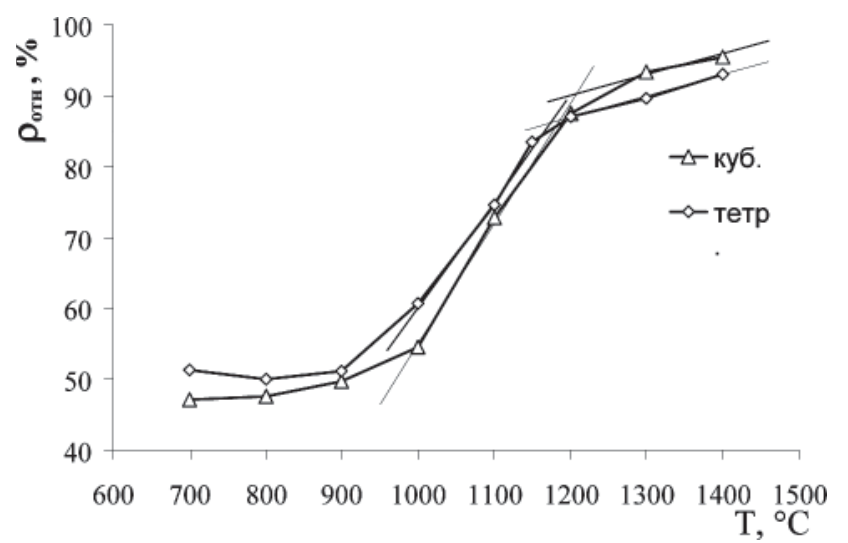

Рис. 1. Зависимость относительной плотности образцов оксида циркония от температуры спекания (куб. - кубический оксид циркония $\left(\mathrm{Zr}_{0,875} \mathrm{Y}_{0,064} \mathrm{Eu}_{0,061}\right) \mathrm{O}_{1,937}$, тетр. - тетрагональный оксид циркония $\left.\left(\mathrm{Zr}_{0,97} \mathrm{Y}_{0,03}\right) \mathrm{O}_{1,985}[9]\right)$

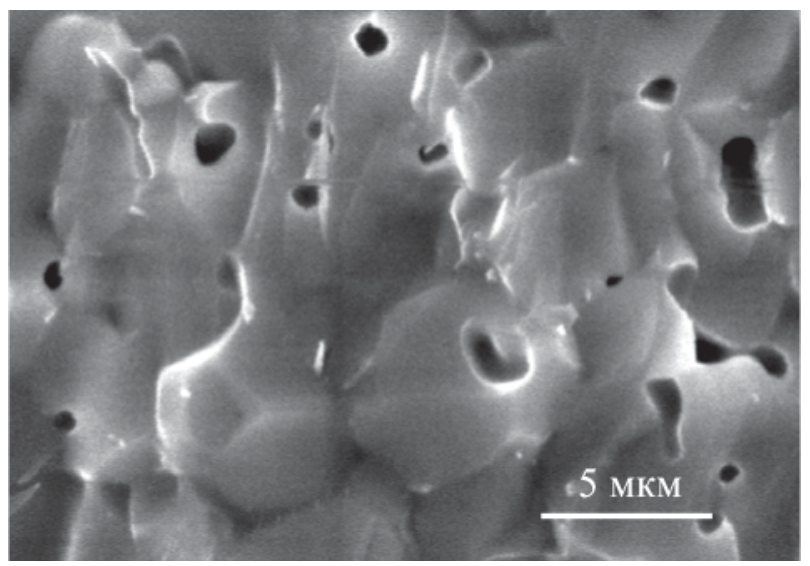

Рис. 2. Микрофотография кубического оксида циркония (сканирующаяся электронная микроскопия, скол, спекание $1400{ }^{\circ} \mathrm{C}, 1$ ч)

Кажущуюся плотность образцов определяли методом гидростатического взвешивания. Относительную плотность рассчитывали как отношение кажущейся плотности к истинной. За истинную плотность брали рентгеновскую $\left(6,12 \pm 0,004\right.$ г $\left./ \mathrm{cm}^{3}\right)$, определенную по параметрам кубической решетки ( $a=0,5148 \pm 0,0001 \mathrm{Hм})$.

Фазовый состав термообработанных образцов определяли методом рентгеновского фазового анализа (РФА) на дифрактометре ДРОН-1,5 (Cu K ширине наиболее интенсивной рентгеновской линии (111) на её полувысоте рассчитывали средний размер зерен [8].

Микроструктуру образцов кубического оксида циркония исследовали на растровом электронном микроскопе РЭММА-202. Образец керамики разрушали сколом, на поверхность которого термическим испарением в вакуумной камере наносился тонкий слой хрома для обеспечения стока электронов.

Экспериментальные результаты. Исходные образцы прессовали из наноразмерного порошка кубического оксида циркония методом осевого холодного прессования при давлении 256 МПа. Зависимость относительной плотности образцов оксида циркония от температуры термообработки имеет три участка (рис. 1). Относительная плотность
Таблица 1. Дифракционные данные кубического оксида циркония

\begin{tabular}{|c|c|c|c|c|}
\hline 20, град & $I, \%$ & $\beta$, град & $\boldsymbol{d}, \AA$ & $h \boldsymbol{k} \boldsymbol{l}$ \\
\hline 30,05 & 100 & 0,20 & 2,9714 & 111 \\
\hline 34,75 & 32 & 0,25 & 2,5795 & 200 \\
\hline 50,12 & 64 & 0,25 & 1,8186 & 220 \\
\hline 59,55 & 48 & 0,30 & 1,5512 & 311 \\
\hline 62,50 & 7 & 0,40 & 1,4848 & 222 \\
\hline
\end{tabular}

Примечание. $I$ - относительные интенсивности рентгеновских линий; $\beta$ - ширины линий на их полувысоте; $d$ - межплоскостные расстояния; $h, k, l-$ индексы плоскостей отражения.

с увеличением температуры термообработки от 700 до $900{ }^{\circ} \mathrm{C}$ остается практически постоянной и составляет 47,6-49,7\%, от 1000 до $1200{ }^{\circ} \mathrm{C}$ - стремительно возрастает до 87,5\% и от 1200 до $1400{ }^{\circ} \mathrm{C}$ возрастает медленнее до 95,4\%. Приведенные результаты свидетельствуют о том, что до $900{ }^{\circ} \mathrm{C}$ образцы не спекаются. Спекание проходит в интервале температур $1000-1400{ }^{\circ} \mathrm{C}$, причем наиболее интенсивно в интервале $1000-1200{ }^{\circ} \mathrm{C}$. В интервале температур $1000-1200^{\circ} \mathrm{C}$ энергия активации спекания составляет 40,1 $\pm 2,1$ кДж/моль. Она значительно снижается до 7,2 $\pm 2,1$ кДж/моль в интервале температур $1200-1400{ }^{\circ} \mathrm{C}$.

Исследование микроструктуры образца, термообработанного при $1400^{\circ} \mathrm{C}$, методом электронной микроскопии (рис. 2) показало, что материал состоит из зерен округлой формы диаметром 4-6 мкм. Материал содержит поры трех интервалов размеров 0,85-1,1 мкм, 0,4-0,6 мкм и 0,2-0,3 мкм. Крупные поры имеют округлую, чаще овальную или неправильную форму, средние и мелкие - округлую.

Исследования фазового состава термообработанных образцов, проведенные методом рентгеновского фазового анализа, показали, что все дифрактограммы содержат рентгеновские линии только кубического оксида циркония (ASTM № 30-1468). Положение каждой рентгеновской линии на дифрактограммах и её относительная интенсивность с учетом точности измерений не зависят от температуры термообработки образца. Параметры решетки кубического оксида циркония для образцов, термообработанных при всех температурах, составляют $a=0,5148 \pm 0,0001 \mathrm{HM}$, а рас-

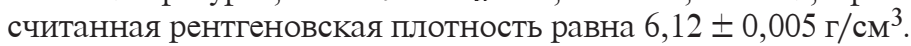
Дифракционные данные образца, термообработанного при $1400{ }^{\circ} \mathrm{C}$, приведены в табл. 1 .

Рентгеновские линии на дифрактограмме образца, термообработанного при $700{ }^{\circ} \mathrm{C}$, имеют значительное уширение. Их ширина на полувысоте составляет от $0,76^{\circ}$ (при угле отражения $2 \theta$, равном $30,05^{\circ}$ ) до $1,05^{\circ}$ (при $2 \theta$, равном $62,5^{\circ}$ ). Это указывает на малый размер (15-18 нм) областей когерентного рассеяния. С увеличением температуры термообработки образцов до $1300{ }^{\circ} \mathrm{C}$ уширение рентгеновских линий уменьшается до инструментального, равного $0,2^{\circ}$. Зависимость среднего размера зерен материала от температуры термообработки образцов представлена на рис. 3. Данные для образцов, термообработанных при температурах 700-1200 ${ }^{\circ} \mathrm{C}$, pacсчитаны по уширению рентгеновских линий на дифрактограммах, а для образца, термообработанного при $1400{ }^{\circ} \mathrm{C}$, размер зерен определен по микрофотографии скола, полученной методом сканирующей электронной микроскопии (см. рис. 2). Видно, что точки, соответствующие интервалам 
температур $700-900{ }^{\circ} \mathrm{C}$ и $900-1400{ }^{\circ} \mathrm{C}$, достаточно хорошо ложатся на прямые линии. Угол наклона к оси абсцисс линии, соответствующей первому интервалу, меньше, чем угол наклона линии, соответствующей второму интервалу. С увеличением температуры от $700{ }^{\circ} \mathrm{C}$ начинается умеренный рост зерен, который ускоряется при $900^{\circ} \mathrm{C}$. Энергии активации роста зерен в интервалах температур 700-900 ${ }^{\circ} \mathrm{C}$ и $900-1400{ }^{\circ} \mathrm{C}$ равны соответственно $12,8 \pm 5,1$ кДж/моль и $191 \pm 10$ кДж/моль.

Обсуждение. Анализ результатов проведенных исследований показывает, что в интервале температур 700-900 ${ }^{\circ} \mathrm{C}$ сохраняется практически постоянное значение плотности на зависимости относительной плотности образцов кубического оксида циркония от температуры спекания (см. рис. 1) и отмечается умеренный рост зерен на зависимости среднего размера зерен от температуры (рис. 3). В интервалах температур $1000-1200{ }^{\circ} \mathrm{C}$ и $1200-1400{ }^{\circ} \mathrm{C}$, в которых отмечается быстрый и медленный рост относительной плотности соответственно, интенсивный рост зерен происходит при 900- $1400{ }^{\circ} \mathrm{C}$. При этом фазовый состав керамического материала не меняется во всем исследованном интервале температур и совпадает с фазовым составом исходного наноразмерного порошка оксида циркония.

В ряде работ зарубежных авторов [4], [10], [11] указывается, что температура спекания $1400^{\circ} \mathrm{C}$ также является оптимальной. При этом достигается относительная плотность 95-97\%. На зависимостях относительной плотности от температуры спекания также имеются интервалы температур быстрого и медленного роста плотности. Однако численные значения интервалов температур различны во всех работах и отличаются от наших данных. Так, по данным американских исследователей [4] быстрый и медленный рост плотности происходит в интервалах температур $1200-1400{ }^{\circ} \mathrm{C}$ и $1400-1500{ }^{\circ} \mathrm{C}$, по данным японских специалистов [10] - в интервалах температур $1200-1300{ }^{\circ} \mathrm{C}$ и $1350-1500{ }^{\circ} \mathrm{C}$, а по данным авторов работы [11] - в интервалах температур $1150-1300{ }^{\circ} \mathrm{C}$ и $1350-1500{ }^{\circ} \mathrm{C}$. По нашим данным быстрый и медленный рост плотности происходит при более низких температурах - 1000$1200{ }^{\circ} \mathrm{C}$ и $1200-1400{ }^{\circ} \mathrm{C}$, хотя при этом относительная плотность исходных образцов наших и зарубежных авторов составляла $45-48 \%$.

Сравнение зависимостей относительной плотности от температуры спекания кубического и тетрагонального оксидов циркония (см. рис. 1) свидетельствует о том, что хотя интервалы температур быстрого и медленного роста плотности совпадают, наклон касательной в интервале температур быстрого роста у кубического оксида больше, чем у тетрагонального. Наклоны касательных в интервале температур медленного роста относительной плотности для кубического и тетрагонального оксидов совпадают. Энергия активации спекания кубического оксида циркония в интервале температур быстрого роста относительной плотности несколько больше (40,1 кДж/моль), чем у тетрагонального (32,4 кДж/моль), а в интервале температур медленного роста плотности энергии активации обоих оксидов практически совпадают (7,2 кДж/моль и 7,1 кДж/моль). Повидимому, присутствие оксида европия в кубическом оксиде циркония приводит к увеличению энергии активации спекания в интервале температур быстрого роста плотности.

В работе иранских ученых [11] зависимость размера зерен от температуры термообработки, как и в нашей работе, имеет два участка: умеренного и интенсивного роста зерен, но в интервалах температур $950-1250{ }^{\circ} \mathrm{C}$ и $1300-1500{ }^{\circ} \mathrm{C}$

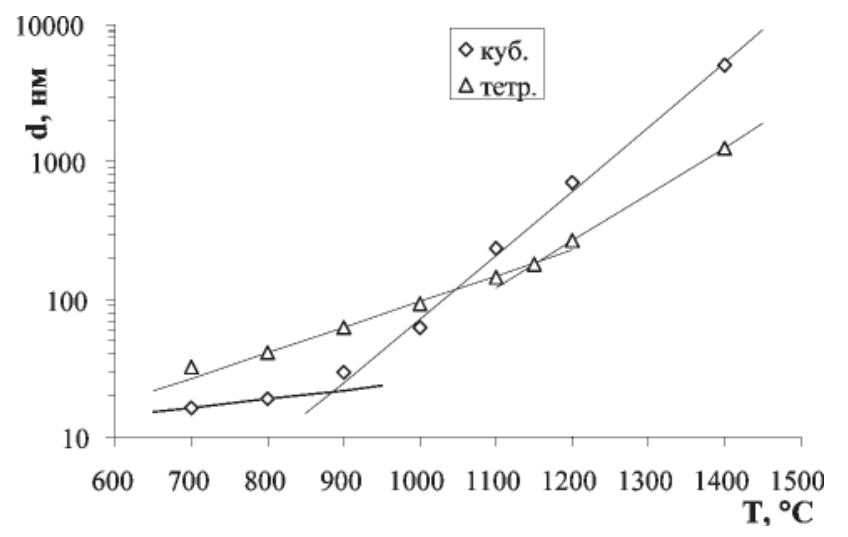

Рис. 3. Зависимость среднего размера зерен от температуры спекания (куб. - кубический оксид циркония $\left(\mathrm{Zr}_{0,875} \mathrm{Y}_{0,064} \mathrm{Eu}_{0,061}\right) \mathrm{O}_{1,937}$; тетр. - тетрагональный оксид циркония $\left(\mathrm{Zr}_{0,97} \mathrm{Y}_{0,03}\right) \mathrm{O}_{1,985}$ [9])

соответственно, что существенно превышает аналогичные данные нашей работы: $700-900{ }^{\circ} \mathrm{C}$ и $900-1400{ }^{\circ} \mathrm{C}$.

Зависимости среднего размера зерен от температуры спекания кубического и тетрагонального оксидов циркония (см. рис. 3) свидетельствует о том, что как интервалы температур умеренного и интенсивного роста размера зерен, так и наклон касательных к кривым различны. Если умеренный и интенсивный рост зерен кубического оксида находится в интервалах температур $700-900{ }^{\circ} \mathrm{C}$ и $900-1400{ }^{\circ} \mathrm{C}$, то тетрагонального - 700-1150 ${ }^{\circ} \mathrm{C}$ и $1150-1400{ }^{\circ} \mathrm{C}$ соответственно. Наклон касательных в интервале температур умеренного роста зерен кубического оксида меньше, чем тетрагонального, а в интервале температур интенсивного роста - наоборот. Энергия активации роста зерен кубического оксида циркония в интервале температур умеренного роста существенно меньше (12,8 $\pm 5,1$ кДж/моль), чем тетрагонального (51,5 \pm 4,0 кДж/моль). В интервале же температур быстрого роста, наоборот, энергия активации роста зерен кубического оксида циркония больше (191 \pm 10 кДж/моль), чем тетрагонального $(135 \pm 24$ кДж/моль). Присутствие оксида европия в кубическом оксиде циркония способствует росту зерен в интервале температур 900-1400 ${ }^{\circ} \mathrm{C}$ (в интервале интенсивного роста зерен). Это подтверждает более активное протекание диффузионных процессов в кубическом оксиде циркония по сравнению с тетрагональным.

В работах [10], [11] средний размер зерен кубического оксида циркония, полученного при температуре $1500{ }^{\circ} \mathrm{C}$, составил 2,5 и 2,14 мкм соответственно. Материал имел закрытые поры двух размеров - 0,25...0,35 мкм и 0,1...0,15 мкм как внутри зерен, так и на их границах. По нашим данным, для кубического оксида циркония, полученного при температуре $1400{ }^{\circ} \mathrm{C}$, эта величина равна 5 мкм. Структура материала содержит 4,6\% об. закрытых пор трех интервалов размеров $0,85-1,1$ мкм, 0,4-0,6 мкм и 0,2-0,3 мкм. Размер зерен тетрагонального оксида циркония, полученного при этой же температуре, составил 1-1,4 мкм. Имеются закрытые поры двух интервалов размеров 0,8-1 мкм и 0,20,3 мкм [9]. Средний размер зерен кубического оксида циркония, содержащего оксид европия, при тех же температурах спекания больше, чем у кубического оксида циркония, стабилизированного только иттрием.

Наличие закрытой пористости на уровне нескольких процентов в матричном топливе, мишенях для трансмутации и в матрицах для изоляции радиоактивных отходов 
обязательно [5]. В результате цепной реакции деления урана среди прочих продуктов деления образуются и инертные газы - аргон, криптон и ксенон. При $\alpha$-распаде актиноидов газообразным продуктом распада является гелий. При воздействии потока нейтронов на актиноиды проходят реакции деления и радиационный захват нейтронов, приводящий к образованию тяжелых ядер. Закрытые поры, в основном округлой формы, служат стоками для газообразных продуктов деления и распада. Достаточное количество закрытых пор обеспечит удержание газообразных продуктов деления и распада в матрице и приемлемое их давление для исключения разрушения иммобилизирующего материала.

Полученные результаты дают основание считать, что америций будет способствовать более активному протеканию процессов спекания и роста зерен кубического оксида циркония подобно европию - его имитатору согласно теории Сиборга [6].

\section{Выводы}

Исследовано спекание компактов из наноразмерного порошка кубического оксида циркония, стабилизированного оксидом иттрия и содержащего оксид европия как имитатор оксида америция, в интервале температур 700-1400 ${ }^{\circ} \mathrm{C}$. Термообработка при оптимальной температуре $1400{ }^{\circ} \mathrm{C}$ в течение 1 ч позволяет получить керамический материал с относительной плотностью 95,4 \%, с зернами размерами 4-6 мкм и порами трех интервалов размеров: 0,85-1,1 мкм, 0,4-0,6 мкм и 0,2-0,3 мкм. Показано, что наиболее интенсивно спекание проходит в интервале температур 1000-1200 ${ }^{\circ} \mathrm{C}$, менее активно - в интервале $1200-1400{ }^{\circ} \mathrm{C}$. Энергии активации спекания составляют $40,1 \pm 2,0$ кДж/моль и 7,1 $\pm 2,0$ кДж/моль соответственно.

Зависимость среднего размера зерен кубического оксида циркония от температуры термообработки имеет два участка: умеренного $\left(700-900{ }^{\circ} \mathrm{C}\right)$ и интенсивного $\left(900-1400{ }^{\circ} \mathrm{C}\right)$ роста зерен. Энергии активации роста зерен в указанных интервалах температур равны $12,8 \pm 5,1$ кДж/моль и $191 \pm 10$ кДж/моль соответственно.

Экспериментальные результаты по спеканию и формированию микроструктуры кубического оксида циркония с оксидом европия как имитатором америция убедительно показывают возможность включения радионуклидов америция в керамические матрицы из кубического оксида циркония. Эти данные позволят повысить надежность иммо- билизации актиноидов, уменьшить риски для обслуживающего персонала при возможной переработке отработавшего ядерного топлива и, в конечном итоге, обеспечить защиту биосферы как среды обитания человечества от загрязнения высокотоксичными радионуклидами.

\section{Список литературы}

1. Restani R., Martin M., Kivel N., Gavillet D. Analytical investigation of irradiared inert matrix fuel // J. Nucl. Mat. - 2009. - Vol. 385. P. 435-442.

2. Degueldre $C$. Zirconia inert matrix for plutonium utilization and minor actinides disposition in reactor // J. Alloys and Comp. - 2007. Vol. 445. - P. 36-41.

3. Gibb F. G. F., Taylor K. J., Burakov B. E. The 'granit encapsulation' rout to the safe disposal of $\mathrm{Pu}$ and other actinides // J. Nucl. Mat. - 2008. - Vol. 374. - P. 364-369.

4. Tridandapani R. R., Folgar C. E., Folz D. C. at all. Microwave sintering of $8 \mathrm{~mol} \%$ yttria - zirconia (8YZ): An inert matrix materials for nuclear fuel applications // J. Nucl. Mat. - 2009. - Vol. 284. P. $153-157$.

5. Ажажа В. М., Белоус В. А., Габелков С. В., Неклюдов И. М. и др. Ядерная энергетика. Обращение с отработавшим ядерным топливом и радиоактивными отходами. - К.: Наук. думка, 2006. -253 с.

6. Громов Б.В., Савельев В. И., Шевченко И. Б. Химическая технология облученного ядерного топлива. - М:. Энергоатомиздат, 1983. - 352 c.

7. Габелков С. В., Тарасов Р. В., Полтавцев Н. С. и др. Эволюция фазового состава при термической обработке соосажденных гидроксидов циркония, иттрия и европия // Ядерна та радіаційна безпека. - 2009. -№ 2. - С. 39-43.

8. Уманский Я. С., Скаков Ю. А., Иванов А. Н., Расторгуев Л. Н. Кристаллография, рентгенография и электронная микроскопия. М.: Металлургия, 1982. - 632 с.

9. Габелков С. В., Тарасов Р. В., Полтавиев Н. С. и др. Спекание тетрагонального оксида циркония // Вестник НТУ ХПИ, тем. вып. Химия, химическая технология и экология. -2008 . - № 39. C. $136-144$.

10. Matsui K., Yoshida H., Ikuhara Y. Grain-boundary structure and microstructure development mechanism in 2-8 mol\% yttria-stabilized zirconia polycrystals // Acta Materialia. - 2008. - 56. - C. 1315-1325.

11. Mazaheri M., Zahedi A. M., Hejazi M. M. Processing of nanocrystalline $8 \mathrm{~mol} \%$ yttria-stabilized zirconia by conventional, microwave and two-step sintering // Mat. Sci. \& Engin. A. - 2008. 492. - P. 261-267. 